How to cite: Reckerth, U.D. Mihuleț, E.M.N., Harpa, G.V. Milian, N. (2020) Analysis of 2019 Convective Season in Transylvania. 2020 "Air and Water-Components of the Environment" Conference Proceedings, Cluj-Napoca, Romania, p. 291-298, DOI: 10.24193/AWC2020_27.

\title{
ANALYSIS OF 2019 CONVECTIVE SEASON IN TRANSYLVANIA
}

\author{
Udo Dorian RECKERTH ${ }^{1}$, Eugen Marian Nicolae MIHULET⿱ ${ }^{1}$, Gabriela \\ Victoria HARPA ${ }^{1,2}$, Narcisa MILIAN ${ }^{1}$
}

DOI: 10.24193/AWC2020 27

\begin{abstract}
The purpose of this study is the identification of the areas with an increased frequency of convective developments, especially those affected by hail. All convective cells accompanied by hail, developed in the 2019 warm season in Bobohalma WSR-98D coverage radius were analyzed, in order to determine their areas of action in May-September 2019, as well as the mesocyclones detected. With the help of a soft created in Python programming language and developed within South - Transylvania Regional Forecast Center - Sibiu, all the signals with hail larger than 0.5 inches $(1.27 \mathrm{~cm})$ were extracted from the hail algorithms generated by the Principal User Processor (PUP).
\end{abstract}

Keywords: weather radar, hail, mesocyclone

\section{INTRODUCTION}

Nowadays the Doppler Weather Radar System is a key facility for not only weather forecast, but also human being daily life. WSR-98D has been developed based on WSR-88D technology and further explored by merging advanced new technical progress and improving the radar systems configuration from both hardware and software aspects (Zhang J. et all, 2002).

A distinct strength of the WSR-88D is the meteorological pattern recognition and processing capability of the system. These computer programs are called "algorithms" (***, 1990). Each is geared toward producing a PUP (Principal User Processor) displayable "derived" product that either answers an operational question (the speed and direction of storm motion or Storm Track Information, STI) or provides an alternate, processed volumetric view of base data designed to help measure storm severity (Vertically Integrated Liquid, VIL; Green and Clark, 1972). Most, but not all, of the current suite of algorithms are designed for application to the convective storm (Lemon L.R., 1999).

\footnotetext{
${ }^{1}$ Regional Meteorological Center Transilvania Sud, Sibiu, 49 Someşului str, 550003 Sibiu, Romania, email: udo.reckerth@gmail.com

${ }^{2} \mathrm{PhD}$ candidate, Faculty of Geography, Babes-Bolyai University, 5-7, Clinicilor Street, 400006, Cluj-Napoca, Romania, email: harpa_gabriela@yahoo.com
} 
The Local Radar base reflectivity product is a display of echo intensity (reflectivity) measured in dBZ (decibels). Radar reflectivity is the amount of transmitted power returned to the radar receiver after hitting precipitation, compared to a reference power density at a distance of 1 meter from the radar antenna.

The HAD (Hail Detection Algorithm) searches for high values of reflectivity above the freezing level. The reflectivity values used are the maximum of cell components, as long as those values are above the freezing level. Values below that level are ignored.

For the calculation of $\mathrm{POH}$ (Probability of Hail), the location of the highest reflectivity of at least $45 \mathrm{dBZ}$ above the freezing level is found. The greater the height above the freezing level, the greater the POH. In the calculation of POSH (Probability of Severe Hail) and MEHS (Maximum Expected Hail Size), reflectivity greater than $40 \mathrm{dBZ}$ that are present above the freezing level are used. In addition, a weighting factor is used, such that the greater the reflectivity value above $40 \mathrm{dBZ}$ and the greater the altitude of this value, the greater the weighting factor. Reflectivity greater than $50 \mathrm{dBZ}$ and those at altitudes higher than the altitude of the $-20^{\circ} \mathrm{C}$ isotherm, carry the most weight (Lemon L.R., 1999).

The basis of all mesocyclone detection algorithms (MDA) is the automated pattern recognition of an area of rotation in Doppler radar radial velocity data. Because only the component of airflow directly toward or away from the radar (along-radial) is measured, areas of rotation appear as a couplet of strong localized opposing flows (outbound velocities next to inbound velocities at approximately constant range).

WSR-88D data are collected in volume scans consisting of a series of 3608 antenna sweeps at constant elevation. Each consecutive sweep is taken with increasing elevation angle. The algorithm first processes data at the one-dimensional (1D) level; shear segments of cyclonic azimuthal shear are detected. Next, the shear segments are horizontally associated to form two-dimensional (2D) features. MDA uses vertical association to create three-dimensional (3D) detections at the end of each volume scan. Finally, time association is employed to complete the process (Stumpf, G. J. et al 1998).

\section{DATA AND METHODS}

We have gathered all the hail events from the meteorological stations inside the radar coverage area and all the signals from the radar hail algorithm in 2019, using a soft developed in Python programming language. All data was collected in chronological order, specifying the latitude, longitude, cells ID and hail size as they appear in PUP application.

After applying different filters, the events were plotted on maps using ArcMap application from ArcGIS software to highlight the most severe cells and their areas of occurrence. In the end, we have plotted some comparative graphs in order to 
recognize the measured hail in radar algorithm and to highlight the areas with most frequent hail events.

\section{RESULTS}

In Figure 1 it is plotted the spatial distribution of the hail cases observed at the meteorological stations in May-September 2019 to highlight the areas with a higher frequency of hail events.

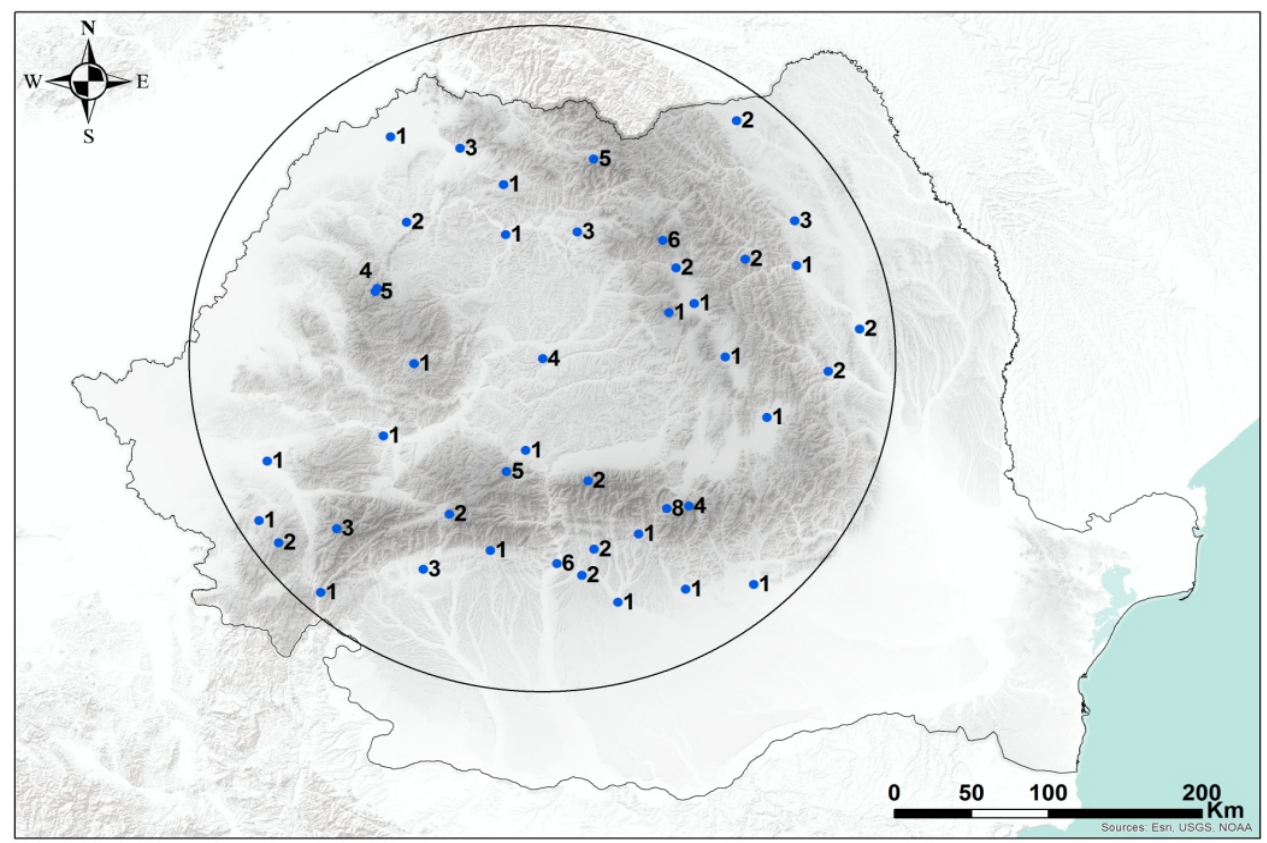

Fig. 1. Number of hail cases at the meteorological stations in May-September 2019

Two comparative graphs of the known hail diameters from the meteorological stations were plotted, versus the diameters provided by the Hail Detection Algorithm for those specific events (Fig. 2 and 3).

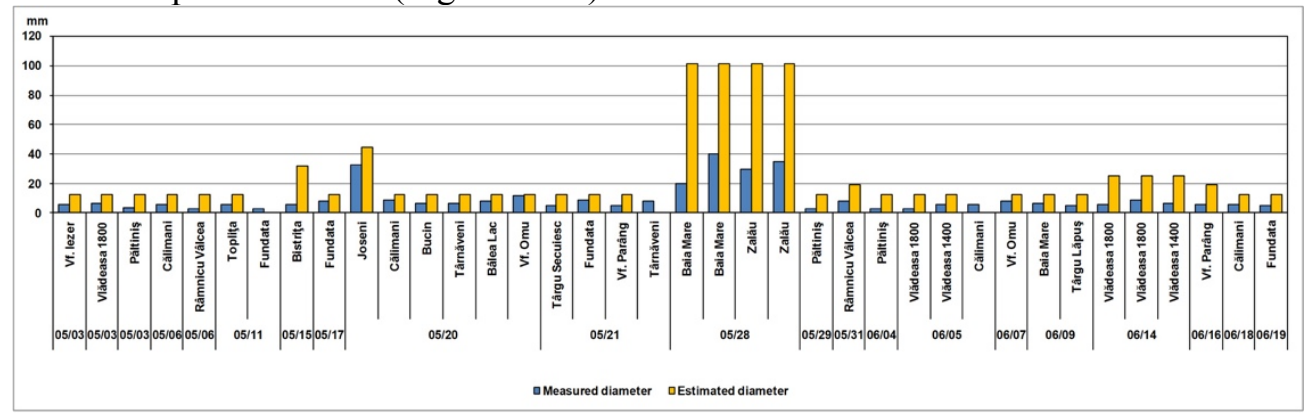

Fig. 2. Hail diameters from meteorological stations vs HDA estimations (May-June 2019) 
We must specify that the measured hail in a storm is not necessarily the largest hail occurred in the area, so in the most cases the estimated/expected hail size (according to HDA) is greater than the measured one. There were also some cases of vetch at the mountain stations or of hail at the radar location with no values from the Hail Detection Algorithm, in the first case due to low values of radar reflectivity in the cold clouds over the mountains and in the second case due to the "cone of silence" above the radar, where the volume of air cannot be scanned.

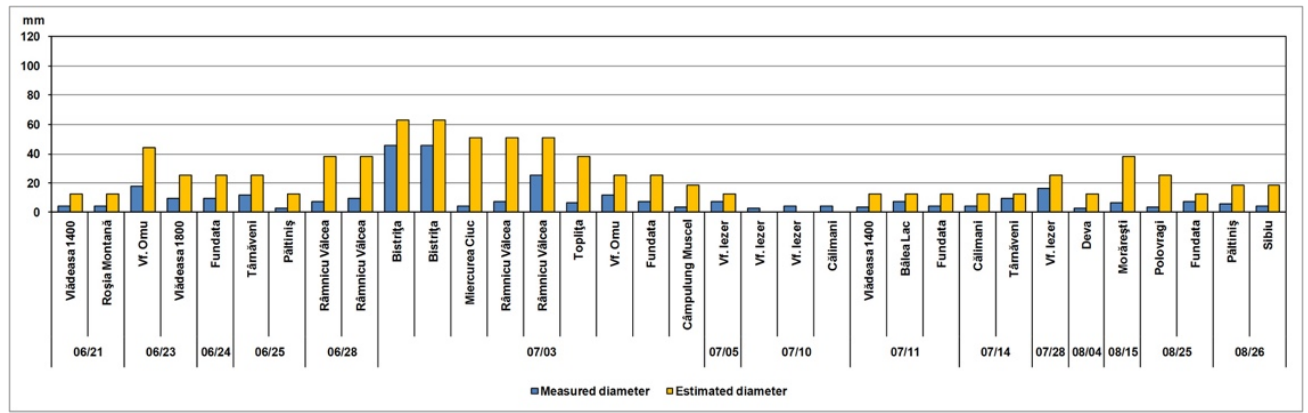

Fig. 3. Hail diameters from meteorological stations vs HDA estimations (June-September 2019)

Below, in figure 4 and 5 there were plotted al the hail estimations from HDA for hail larger than $0.5,1.0$ and 2.0 inch $(1.27,2.54$ and $5.08 \mathrm{~cm})$. We consider the data within the $150 \mathrm{~km}$ circle more reliable, due to radar errors that occur at longer distances.

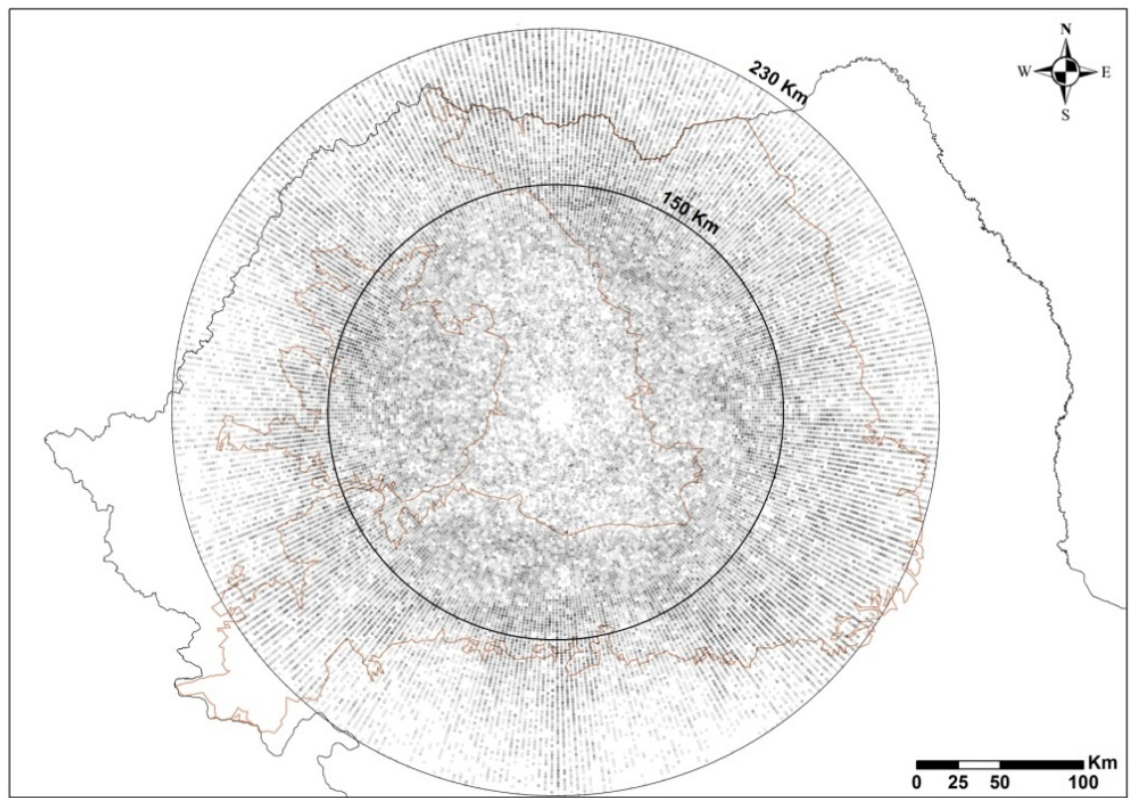

Fig. 4. Hail estimations from HAD, larger than 0.5 inch $(1.27 \mathrm{~cm})$ in Transylvania 


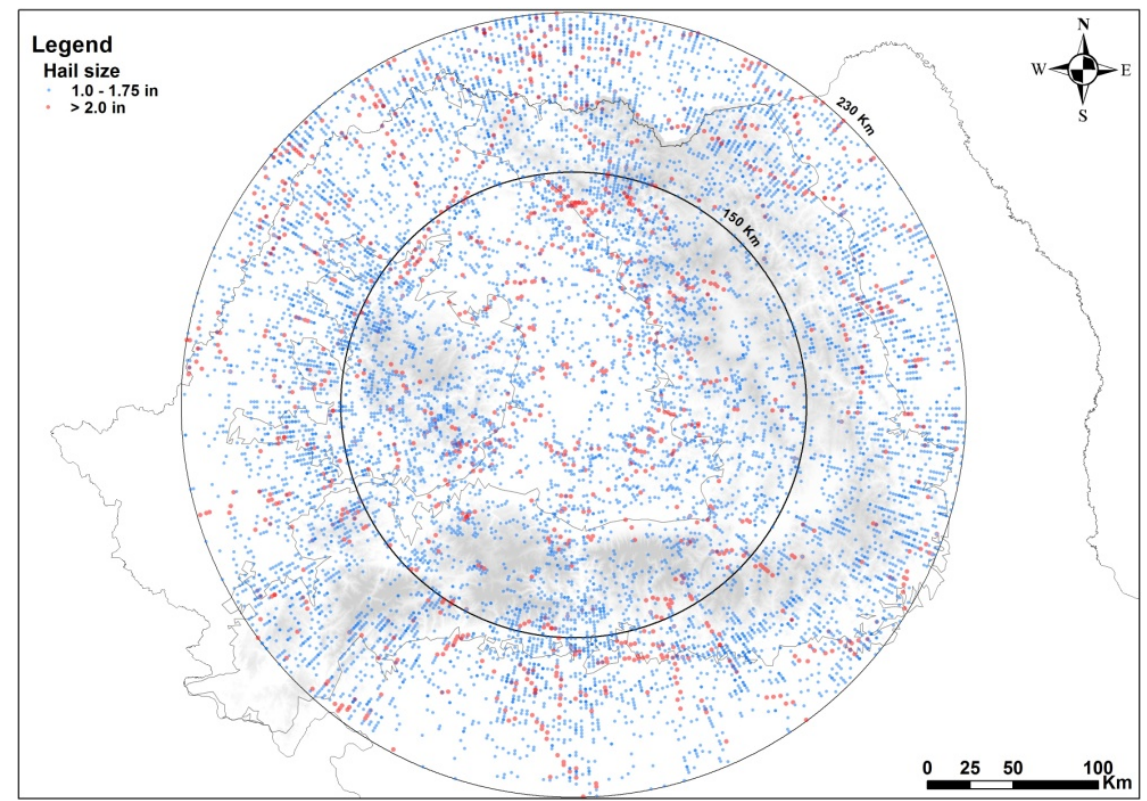

Fig. 5. Severe Hail estimations from HAD, larger than 1.0 and 2.0 inch $(2.54$ and $5.08 \mathrm{~cm})$

In figure 6 there are plotted all the mesocyclones detected by the Mesocyclone Detection Algorithm of the WSR-98D radar from Bobohalma in May-September 2019 , the initiation points of the convective cells that generate them with green dots, the trajectory, the areas where the mesocyclones appeared with purple dots and the dissipation points of the convective clouds with red dots.

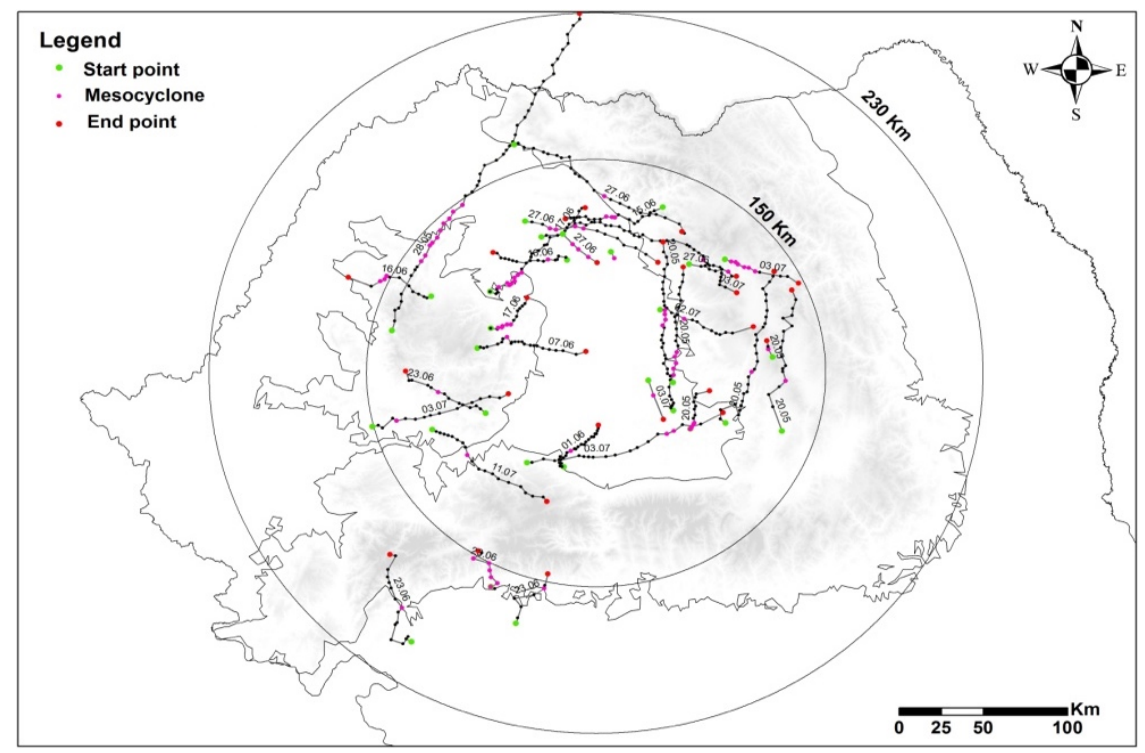

Fig. 6. Mesocyclones trajectories in Transylvania in 2019 (May-September) 
The figures 7 -10 are captions from PUP application of clouds reflectivity combined with the Mesocyclone Detection Algorithm, in 4 days with severe storms accompanied by hail.

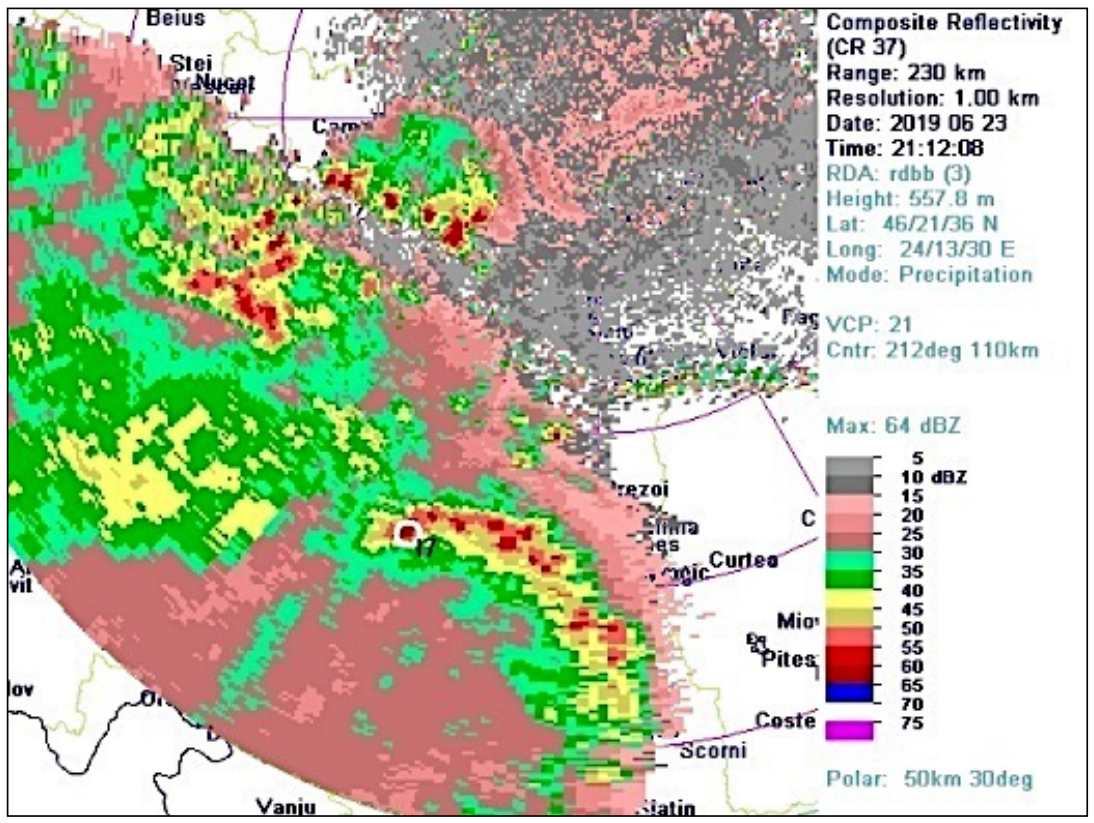

Fig. 7. Mesocyclones in 23 June 2019

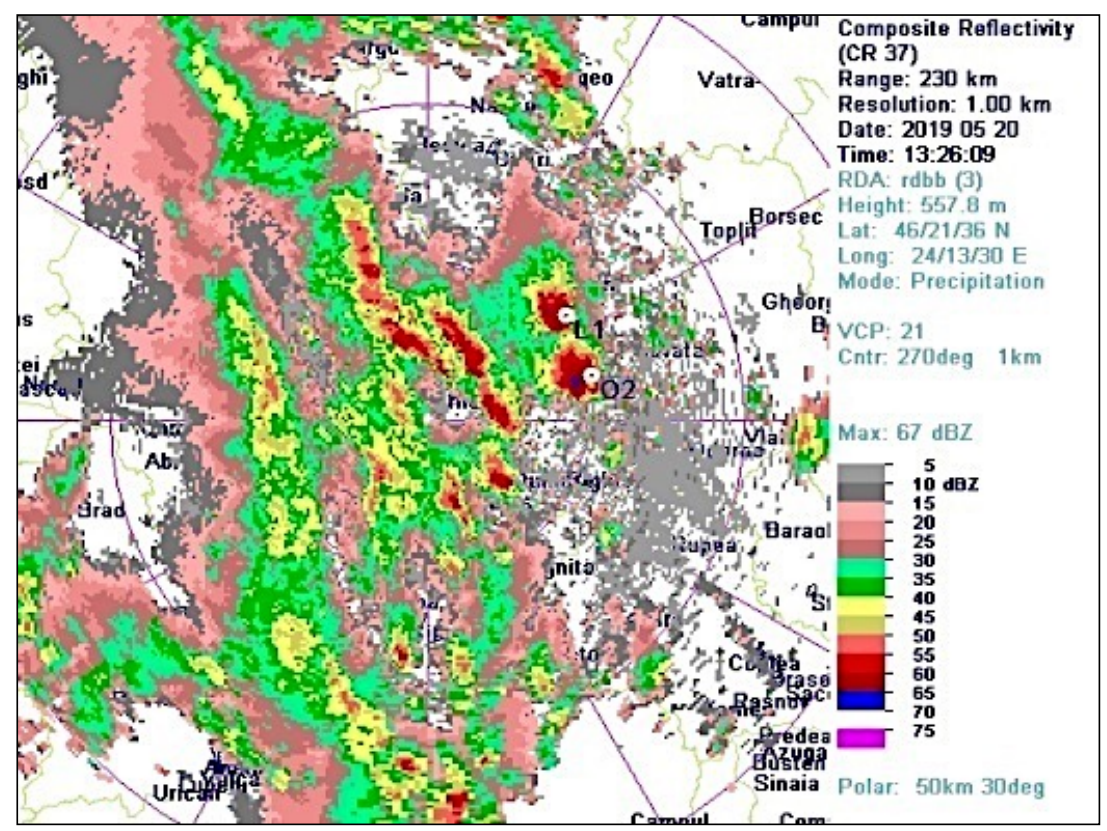

Fig. 8. Mesocyclones in 20 May 2019 
The presence of a mesocyclone is marked with yellow or white small circle. Frequently, the mesocyclones appear in the storms formed along a squall line. Individual cells usually last 30 to 60 minutes, while a squall line may last for several hours.

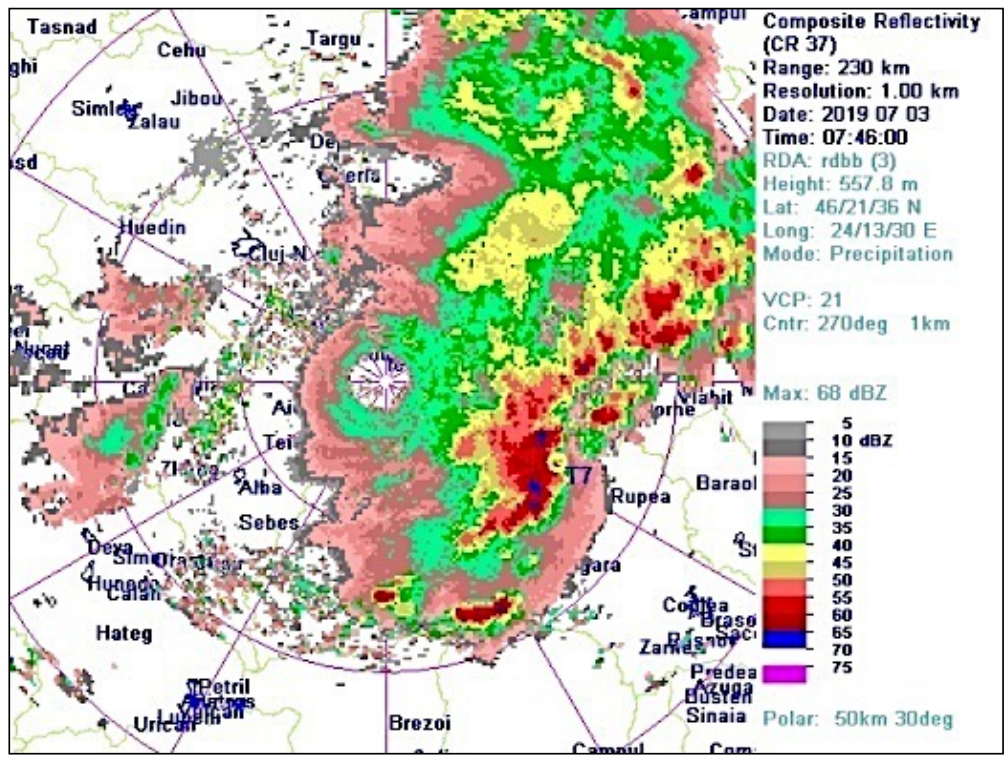

Fig. 9. Mesocyclones in 03 July 2019

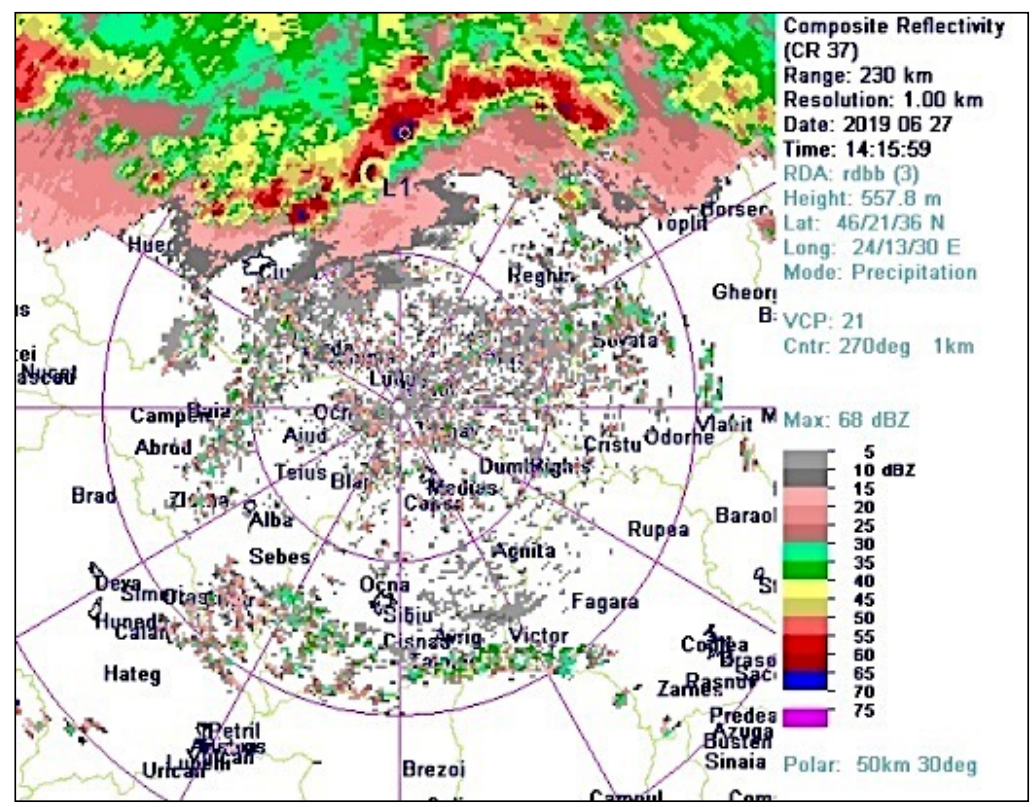

Fig. 10. Mesocyclones in 27 June 2019 


\section{CONCLUSIONS}

Hail distribution from the Hail Detection Algorithm indicates a higher frequency in the mountain areas and in some areas of convergence, specific to the complex relief in Transylvania, related also with the cases of hail from the meteorological stations. The mesocyclones didn't have preferential directions of movement and they have formed where the conditions where favorable, mainly in the presence of a wind shear which represent a change of wind speed and/or direction with height but also with respect to the mesoscale conditions what influenced their trajectory. However, due to the typical atmospheric circulations affecting Transylvania, there is a higher probability of supercells associated with mesocyclones in the northern and eastern part of Transylvania.

Although we have analyzed only one convective year, the importance of this study in operational forecasting is that as a forecaster you must pay attention to the areas with higher frequency in hail events and mesocyclones, and be aware that in most cases the measured hail is probably not the biggest in the area.

\section{REFERENCES}

1. Greene D., Clark R., (1972), Vertically integrated liquid water: A new analysis tool. Monthly Weather Review, 100, 548-552.

2. Gregory J. and all, (1997), The National Severe Storms Laboratory Mesocyclone Detection Algorithm for the WSR-88D, AMS June 1998, https://doi.org/10.1175/15200434(1998)013<0304:TNSSLM>2.0.CO;2

3. Lemon L.R. (1999), WSR-88D/98D Operational Capabilities and Applications, Weather and Biological Targets, Radar, Severe Storms, \& Research Meteorologist

4. Stumpf, G. J., Witt A., Mitchell D., Spencer P., Johnson J.T., Eilts M., Thomas K.W., Burgess D.W., (1997), The National Severe Storms Laboratory Mesocyclone Detection Algorithm for the WSR-88D, Weather and Forecasting 13, 304-326

5. Zhang J., Gao Y., Xu B., (2002), WSR-98D with Powerful Performance and More Friendly Interface to Users, WMO TECO-2002, Bratislava

6. ***, (1990): Federal Meteorological Handbook 11, Washington, DC. 